Publisher: ELSEVIER SCIENCE BV, PO BOX 211, 1000 AE AMSTERDAM, NETHERLANDS

Subject Category: Chemistry, Analytical

DOI:10.1016/S0039-9140(01)00550-1

ISSN: 0039-9140

http://www.sciencedirect.com/science? ob=ArticleURL\& udi=B6THP-44MWNMJ-

$2 \&$ user $=2347467 \&$ coverDate $=01 \% 2 F 04 \% 2 F 2002 \&$ alid $=1140645672 \&$ rdoc $=3 \&$ fmt $=$ high \& orig $=$ search\&_cdi $=5288 \&$ sort $=r \&$ docanchor $=\& v i e w=c \&$ ct $=6 \&$ acct $=C 000057013 \&$ _version=1\&_urlVersion=

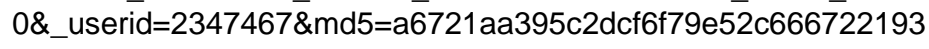

\title{
METHOD FOR THE SIMULTANEOUS DETERMINATION OF TOTAL POLYPHENOL AND ANTHOCYAN INDEXES IN RED WINES USING A FLOW INJECTION APPROACH
}

\section{J. González-Rodríguez ${ }^{1}$, P. Pérez-Juan ${ }^{1}$ and M.D. Luque de Castro ${ }^{2 *}$}

1 R\&D Department Pérez Barquero, S.A. Avda. de Andalucía, 27, E-14550, Montilla, Córdoba, Spain. Fax: 957 650208, E-mail: barquero@fiab.es

${ }^{2}$ Analytical Chemistry Division, Campus of Rabanales. Annex C-3 Córdoba. Spain. Fax: 34-957-218615, E-mail: qa1lucam@uco.es

\begin{abstract}
A simultaneous and fast method for the determination of total polyphenol index (t.p.i.) and total anthocyan index (t.a.i.) has been developed by a flow injection approach and a diode array spectrophotometer for monitoring at $280 \mathrm{~nm}$ and 520 $\mathrm{nm}$, respectively. Linear ranges were obtained from 20 to 70 index units and from 20 to $500 \mathrm{mg} \mathrm{l}^{-1}$ for t.p.i. and t.a.i., respectively. The results provided by the proposed method agree with those obtained using the polyphenol index at $280 \mathrm{~nm}$ and the Ribereau-Gayon method for the determination of total anthocyans. The sample throughput was 25-30 samples per hour. Analytical features such as repeatability, reproducibility and detection and quantification limits as well as the results of a robustness study based on the Steiner-Younden procedure are also given.
\end{abstract}

Keywords: spectrophotometry, total polyphenols, anthocyans, flow injection, wine. 


\section{Introduction}

Wine contains variable quantities of different phenolic compounds which play a key role in the flavour, particularly in red wines. They are responsible for some positive tasting characteristics, but also for some rather unpleasant, negative aspects. The ideal method for estimating the phenol content would be that allowing both to define all of these compounds and assay them separately. This is a timeconsuming alternative due to the difficulty of analyzing all these compounds which is not always possible nor necessary.

An overall knowledge of the phenol content of wine, expressed as a numerical value, provides winemakers with enough information about polyphenol concentration. This makes possible to classify wines according to their phenol content and measure the results of a winemaking operation.

The methods used for this measurement must be rapid, the results obtained must be reproducible and include all types of phenols. The Folin-Ciocalteau value [1] uses an oxidizing agent such as potassium permanganate, and the Folin-Ciocalteau reagent (mixture of phosphotungstic and phosphomolybdic acids) which react with phenols due to their reductive properties. A second value is based on the characteristic absorption at $280 \mathrm{~nm}$ of the benzene cycles of the majority of phenols. The latter seems to be preferable to the Folin-Ciocalteau test due to its speedness and precision.
Anthocyans $\left(A_{t}\right)$ are present in wine in different forms: free anthocyans $\left(\mathrm{A}_{\mathrm{f}}\right)$ and anthocyans combined with tannins $\left(A_{c}\right)$, some of which are bleached by $\mathrm{SO}_{2}\left(\mathrm{~A}_{\mathrm{b}}\right)$, while the rest is unaffected $\left(A_{u}\right)$. So, $A_{t}=A_{f}+A_{c}=A_{f}+A_{b}+A_{u}$. There is not an accurate method for assaying anthocyans $\left(A_{t}\right)$, so this value may only be estimated. On the other hand, a global value for $A_{f}+A_{b}$ may be determined $\left(\mathrm{A}_{\mathrm{s}}\right)$, using chemical methods which are based on the properties of anthocyans either of bleaching by sulphur dioxide or colour variation according to $\mathrm{pH}$ changes [2]. Both methods measure $A_{s}$, however the method based on $\mathrm{pH}$ changes is more affected by the presence of free $\mathrm{SO}_{2}$ in wine and then the sulphur dioxide bleaching method is more reliable.

Chromatography techniques such as low and high pressure liquid chromatography provide enough information only from simple and littlepolimerised molecules. In addition, their cost make them unavailable to many wineries. Research in this sense has been developed using different approaches involving [3] or not pretreatment steps $[4,5]$.

There are not methods in the analytical literature for determining both polyphenols and anthocyans in wines. Some references can be found about polyphenols determination, and some of them use flow injection in an attemp of automation. Buitrago et al. [6] developed a method adapted from the Jerumanis one, which involves reaction of polyphenols with ammonium $\mathrm{Fe}$ (III) citrate to form a coloured 
complex that absorbs at $525 \mathrm{~nm}$. Celeste et al. [7] and Peris-Tortajada et al. [8] used the Folin-Ciocalteau reagent for implementing methods for determining total polyphenols by monitoring the reaction products spectrophotometrically at $750 \mathrm{~nm}$. A recent method measures the absorbance at 280 $\mathrm{nm}$ for determining polyphenol contents [9]. Only a method for the determination of anthocyans using flow injection can be found in the analytical literature [10]. Devoted to the determination of some anthocyans, it is based on the coupling of continuous liquidsolid extraction, evaporation, individual separation by HPLC and photometric detection. The method was applied to the determination of malvidin-3-glucoside, cyanidin-3-glucoside, cyanidin-3glucoside and peonidin-3-glucoside as a demonstration of its performance for the most and less concentrated of these compounds in red wine.

The aim of this research was the development of a continuous, flow injection method for the simultaneous determination of total polyphenol index and anthocyan index which allows fast and cheap determinations thus providing winemakers with an appropriate tool for knowing the total content of both groups of compounds in the daily work.

\section{Experimental}

\section{Apparatus and instruments}

The manifold used is outlined in Fig.1. It was built using a four-channel Gilson Minipuls-3 peristaltic pump (Villiers le Bel, France) fitted with a rate selector, two Rheodyne 5041 injection valves (Elkay, Galway, Ireland), one of them used as selecting valve, and PTFE tubing of $0.5 \mathrm{~mm}$ i.d. (Scharlau, Barcelona, Spain). An Agilent 8354 (Madrid, Spain) diode array spectrophotometer equipped with a Hellma 138-QS flow-cell (Hellma, Jamaica, $\mathrm{NY}$ ) and connected to a computer with Hewlett-Packard software for data collection and treatment was also used.

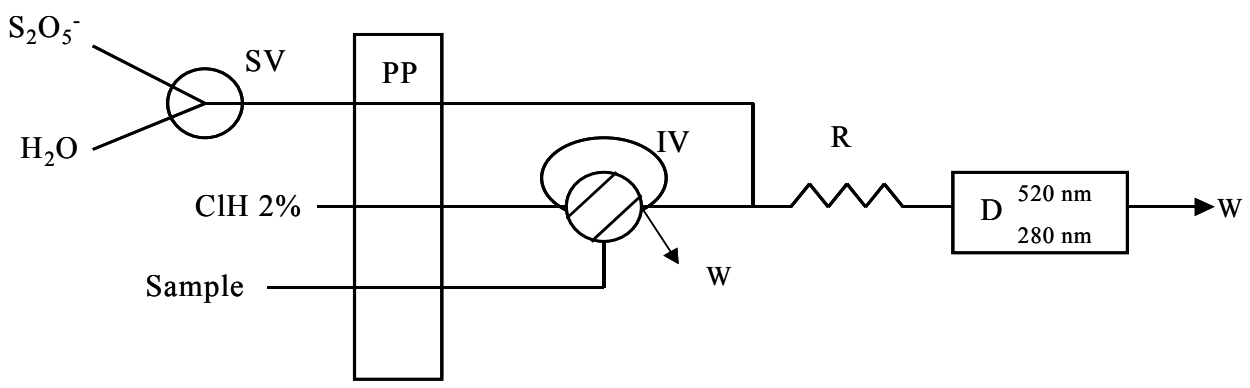

Figure 1. Manifold for the simultaneous determination of total polyphenol index and total anthocyans index in red wine. $\mathrm{PP}=$ peristaltic pump, $\mathrm{SV}=$ selection valve, $\mathrm{IV}=$ injection valve, $\mathrm{R}=$ reactor, $\mathrm{D}=$ detector, $\mathrm{w}=$ waste. 


\section{Reagents and solutions}

Standard solutions both for optimisation studies and calibration were prepared from commercial enocyanin dye (Laffort S.A., Guipúzcoa, Spain), gallic acid (Sigma, Madrid, Spain) and absolute ethanol (Panreac, Barcelona, Spain). The stock solution remained stable for 5 days when stored at $4{ }^{\circ} \mathrm{C}$ in dark.

For the proposed method, the carrier stream was an aqueous solution of $2 \%(\mathrm{v} / \mathrm{v})$ hydrochloric acid and a $2 \%$ $(\mathrm{w} / \mathrm{v})$ potassium pirosulphite solution $\left(\mathrm{K}_{2} \mathrm{~S}_{2} \mathrm{O}_{5}\right)$ was used as a bleaching agent. For the reference method, an aqueous solution of $2 \%(\mathrm{v} / \mathrm{v})$ hydrochloric acid and a $15 \%(\mathrm{w} / \mathrm{v})$ solution of potassium pirosulphite were used.

All solutions were prepared using doubly distilled water of high purity obtained from a Millipore Milli-Q plus system (Bedford, MA).

\section{Reference procedures}

\section{Determination of the total polyphenol index $\left(\mathrm{I}_{280}\right)$}

Wine was diluted with water in a $1: 100$ ratio and the absorbance was directly measured at $280 \mathrm{~nm}$. The value of the $\mathrm{I}_{280}$ was calculated by multiplying the absorbance x 100 .

\section{Determination of the anthocyan index (Ribereau-Gayon method)}

Two samples, each containing $1 \mathrm{ml}$ of wine, $1 \mathrm{ml}$ of ethanol $0,1 \% \mathrm{HCl}$ and 20 $\mathrm{ml}$ of $2 \% \mathrm{HCl}(\mathrm{pH} 0,8)$ were prepared. $4 \mathrm{ml}$ of $\mathrm{H}_{2} \mathrm{O}$ was added to $10 \mathrm{ml}$ of one of the samples and $4 \mathrm{ml}$ of potassium pirosulphite solution, $15 \% \mathrm{w} / \mathrm{v}$, was added to $10 \mathrm{ml}$ of the other and both mixtures were diluted to a double volume. The difference $(\Delta d)$ of absorbance between them was measured at $520 \mathrm{~nm}$ in a $10 \mathrm{~mm}$ path length optical cell. By comparison with a standardised anthocyan solution, the concentration is given by the following equation: $\mathrm{C}(\mathrm{mg} / \mathrm{l})=\Delta \mathrm{d} \times 875$.

\section{Proposed method}

Figure 1 shows the manifold used for the simultaneous determination. The sample was introduced into the loop of the injection valve (IV) by aspiration with the selecting valve (SV) in the position for supplying water. Valve IV was turned to the injection mode and the absorbances at $520 \mathrm{~nm}$ and $280 \mathrm{~nm}$ were monitored. The data thus obtained enabled both calculation of the value of total polyphenol index (t.p.i.) through the value of the absorbance at $280 \mathrm{~nm}$ and provided the value of absorbance at $520 \mathrm{~nm}$ before bleaching by $\mathrm{SO}_{2}$ for the determination of the total anthocyan index (t.a.i.). After this, SV was switched to the position for aspirating $\mathrm{K}_{2} \mathrm{~S}_{2} \mathrm{O}_{5}$ and a new sample aliquot was injected. The absorbance at $520 \mathrm{~nm}$ was now lower as a consequence of bleaching of the fraction of anthocyans combined with tannins $\left(A_{b}\right)$. The difference of absorbance between the two measurements at $520 \mathrm{~nm}$ gave the $\mathrm{A}_{\mathrm{s}}$ value.

\section{Results and discussion}

Optimisation of the method 
The variables which affect the method for the determination of total anthocyan index (t.a.i.) and total polyphenol index (t.p.i.) were studied by a multivariate approach. These variables were optimised, first for anthocyans determination and then for the total polyphenol index. A compromise value from the optimal values obtained individually was adopted, as shown in Table 1.

Table 1. Optimisation of variables

\begin{tabular}{lll}
\hline Variable & $\begin{array}{l}\text { Tested } \\
\text { range }\end{array}$ & $\begin{array}{c}\text { Compromise } \\
\text { value }\end{array}$ \\
\hline $\begin{array}{l}\text { Chemical } \\
\mathrm{K}_{2} \mathrm{~S}_{2} \mathrm{O}_{5}\end{array}$ & $0.4-15$ & 4 \\
$(\% \mathrm{w} / \mathrm{v})$ & & \\
$\mathrm{HCl}(\%$ & - & 2 \\
$\mathrm{v} / \mathrm{v})$ & & \\
$\underline{\mathrm{FI}}$ & & \\
$\mathrm{Q}_{1}=\mathrm{q}_{2}=\mathrm{q}_{3}$ & $0.4-1.2$ & 0.8 \\
$\left(\mathrm{ml} \mathrm{min}{ }^{-1}\right)$ & & \\
$\mathrm{IV}(\mu \mathrm{l})$ & $50-400$ & 50 \\
$\mathrm{R}(\mathrm{cm})$ & - & 50 \\
\hline
\end{tabular}

Figure 2a shows a plot of the absorbance values versus the sample volume $(\mu \mathrm{l})$ and flow-rate $\left(\mathrm{ml} \mathrm{min}{ }^{-1}\right)$ in the optimisation of these variables for the anthocyans method. The response surface shows that the highest values of absorbance are obtained with the largest sample volumes and the lowest values of flow-rate.

Figure 2.b shows a similar plot for the total polyphenol index. A plateau of high absorbance (ca. 3 absorbance units) is observed for a sample volume of $300 \mu \mathrm{l}$ or higher at any flow-rate.
Absorbances close to 1.5 are obtained for t.p.i. using a sample volume of $75 \mu \mathrm{l}$ and a flow-rate of $0.8 \mathrm{ml} \mathrm{min}{ }^{-1}$. With these values of the variables the absorbance is 0.5 for the same sample for t.a.i. A sample volume of $75 \mu \mathrm{l}$ and a flow-rate of $0.8 \mathrm{ml} \mathrm{m^{-1 }}$ were selected for further experiments.

Figure 2.c shows the surface obtained by plotting the absorbance versus anthocyan ( $\mathrm{mg} \mathrm{l}^{-1}$ ) and pirosulphite $(\% \mathrm{~m} / \mathrm{v})$ concentrations. The curve shows a constant absorbance for pirosulphite concentrations of $4 \%$ or higher for all anthocyans range of concentrations. For this value (4\%), the slope of the calibration curve was the highest.

The maximum values of absorbance obtained with higher pirosulphite concentrations were not chosen due to both the agressive nature of pirosulphite for the respiratory system and the good response obtained with $4 \%$ pirosulphite.

The concentration of hydrochloric acid used as carrier was not optimised and was established at $\mathrm{pH} 0.8$ required in order to maintain anthocyans in flavinium cationic form. This $\mathrm{pH}$ did not modify the absorbace of polyphenols at $280 \mathrm{~nm}$. This fact was checked in batch.

The reactor $\mathrm{R}$ had as a function to provide appropiate reagent/sample mixture before reaching the detector. A length of $50 \mathrm{~cm}$ was sufficient for this purpose.

\section{Characterisation of the method}

\section{Calibration curves}


A preliminary calibration curve for each analyte was run separately using standardised solutions of gallic acid and enocyanin previously analised in duplicate by the reference method. Then, calibration curves were run for both compounds in mixture. Six standard solutions containing both analytes were prepared with concentrations between 20 and $500 \mathrm{mg}$ of anthocyans $1^{-1}$ for anthocyans and between 20 and 70 in $I_{280}$ units for the total polyphenol index. Linear responses were found in the range of concentrations studied. There was not interference of each group of compounds in the determination of the other. All standard were prepared weekly and sonicated before use in order to avoid irreproducibility due to

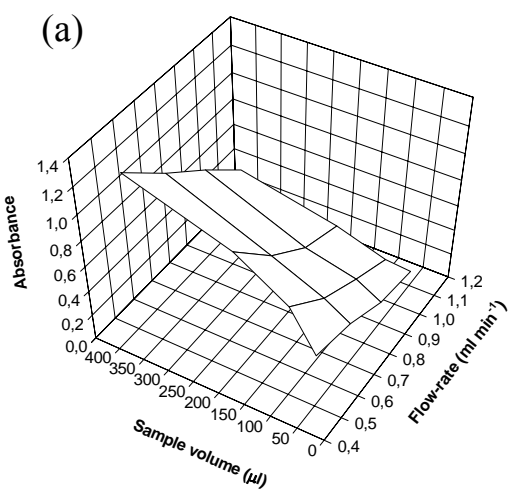

(b)

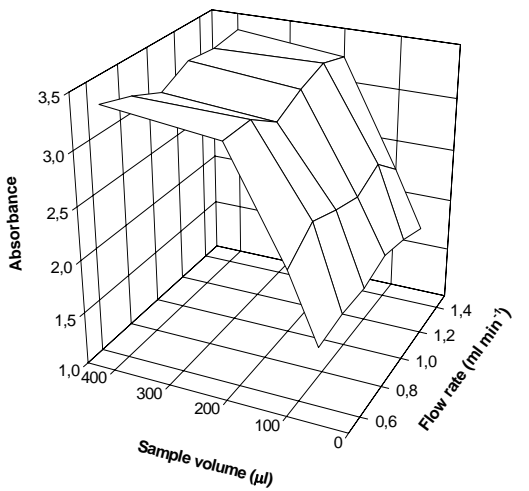

(c)

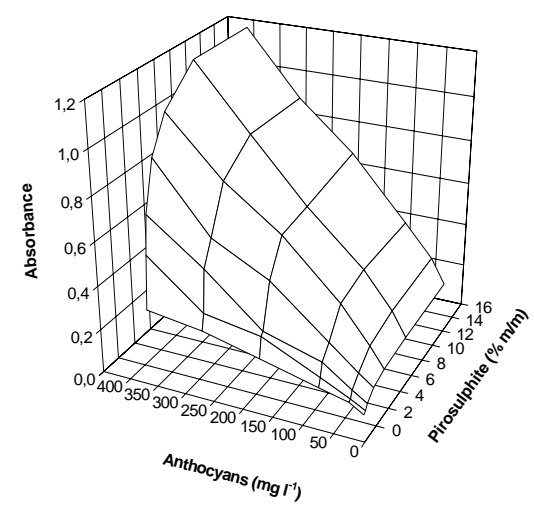

Figure 2. Evolution of absorbance versus sample volume and flow rate in the optimisation of total polyphenol index (a) and anthocyan index (b). Evolution of absorbance versus anthocyan and pirosulphite concentrations for the optimisation of total anthocyan index (c). 
oxidation and/or precipitation of the anthocyans, respectively.

\section{Assessment of the proposed method}

Thirty different red wines were used in the assessment study. Each datum was the average of three determinations. The protocol for assessment consisted of studying analytical parameters such as linear range, traceability with a reference method, repeatability, reproducibility, detection and quantification limits and sample throughput. A robustness study was also developed.

Repeatability ( $r$ ). The Snedecor test was applied in order to establish if the differences between repeatability of the methods were significant. With this aim, the Fobs $=\mathrm{S}_{\mathrm{r}}^{2} / \mathrm{S}_{\mathrm{ref}}^{2}$ was compared with the $F_{1-\alpha}$ obtained from Snedecor tables for $\alpha=0.05$ ( $\mathrm{P}=95 \%)$. As can be observed in Table 2, Fobs $<\mathrm{F}_{1-\alpha}$, so the repeatabilities of the FI and reference method are similar for both parameters.

Table 2. Analytical characteristics of the method

\begin{tabular}{|c|c|c|c|c|}
\hline \multirow[t]{2}{*}{ Parameters } & \multicolumn{2}{|c|}{ Reference } & \multicolumn{2}{|c|}{ Flow injection } \\
\hline & t.p.i. & t.a.i. $*$ & t.p.i. & t.a.i. $*$ \\
\hline Repeatability $\left(\mathrm{mg} \mathrm{l}^{-1}\right)^{*}$ & 1.021 & 4.232 & 2.122 & 6.233 \\
\hline $\mathrm{S}_{\mathrm{r}}\left(\mathrm{mg} \mathrm{l}^{-1}\right)^{*}$ & 0.032 & 0.061 & 0.043 & 0.081 \\
\hline Reproducibility $\left(\mathrm{mg} \mathrm{l}^{-1}\right)^{*}$ & 2.312 & 9.232 & 3.012 & 12.213 \\
\hline $\mathrm{S}_{\underline{\underline{R}}}\left(\mathrm{mg} \mathrm{l}^{-1}\right)^{*}$ & 0.091 & 0.802 & 0.123 & 1.083 \\
\hline Fobs $^{r}$ & - & - & 1.810 & 1.760 \\
\hline Fobs $^{\mathrm{R}}$ & - & - & 1.830 & 1.820 \\
\hline $\mathrm{F}_{1-\alpha}(\mathrm{n}=30)$ & - & - & 1.840 & 1.840 \\
\hline $\operatorname{LOD}\left(\mathrm{mg} \mathrm{l}^{-1}\right)$ & 0.231 & 0.953 & 0.229 & 0.543 \\
\hline LQ $\left(\mathrm{mg} \mathrm{l}^{-1}\right)$ & 0.455 & 1.380 & 0.530 & 1.110 \\
\hline Sample throughput $\left(\mathrm{h}^{-1}\right)$ & 40 & 3 & $25-30$ & \\
\hline
\end{tabular}

Reproducibility ( $R$ ) (30 days).Table 2 shows the $R$ values obtained as well as the results from the application of the Snedecor test: the reproducibility of the
FI method is similar to that of the reference method. In general the reproducibility of both methods is low due to the presence of particles in sus- 
(a)

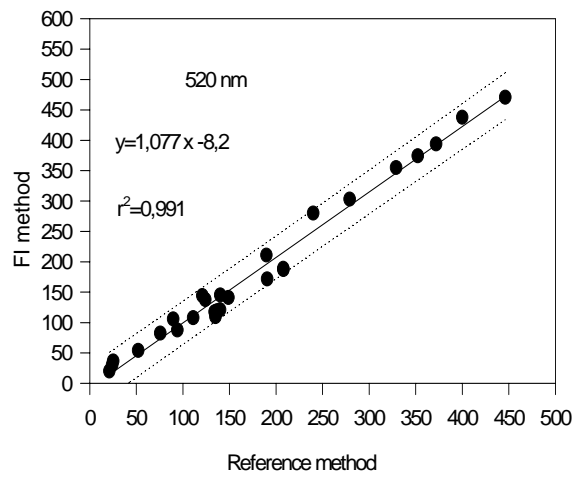

(b)

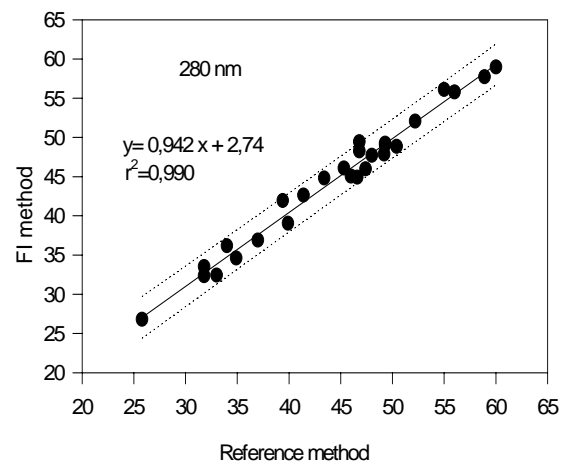

Figure 3. Correlation graphs of the reference method versus the FI method for the determination of total anthocyan index (a) and total polyphenol index (b). Interval of confidence $95 \%$.

pension which produce random light scattering. The errors caused by this phenomenon are within the allowed limits.

Detection (LOD) and quantification (LQ) limits. Table 2 shows that the best LOD corresponds to the FI method for total anthocyan index and that both the reference and FI method yield similar values for the total polyphenol index. Similar behaviour shows the quantification limit.

Traceability. The traceability of the methods was studied by comparing the results obtained from 30 samples of different red wines analysed by both the reference and proposed method. Figure 3.a shows the regression of the flow injection method for t.a.i. versus the reference method. The regression equation, $\mathrm{Y}=1.077 \mathrm{X}-8.2 \quad(\mathrm{r}=0.991)$ shows good correlation between both methods. Correlation between t.p.i. FI method and the reference method is shown in figure 3.b. The regression equation is $\mathrm{Y}=0.942 \mathrm{X}+2,74(\mathrm{r}=0.990)$. Confidence limits of $95 \%$ are shown in figures 3.a and 3.b in discontinuous lines. In both cases traceability was assured using the t-test. The low correlation factor can be partially owing to the unaccuracy of the reference methods used in both determinations (t.a.i. and t.p.i.).

Sample throughput.The results in Table 2 show that the FI method has a global frequency higher than the reference methods made sequentially. Though the reference method for determining the total polyphenol index is a bit fastest than the t.p.i. FI method, the highest sampling rate of the t.a.i. FI method as compared with the t.a.i. reference can justify by itself the use of the proposed method. 
Robustness study. The study was developed using the Younden-Steiner procedure. Critical variables of the system are hydrochloric acid and pirosulphite concentrations and flowrate. These variables were modified $\pm 25 \%$ of their optimum values. No significant changes were observed in any case for the total polyphenol index determination. In the case of total anthocyan index no significant changes were observed by increasing the $\mathrm{HCl}$ and $\mathrm{K}_{2} \mathrm{~S}_{2} \mathrm{O}_{5}$ concentrations. A $5 \%$ decrease in the analytical signal can be observed when decreasing the pirosulphite concentration and no significant variation in the case of $\mathrm{HCl}$. The flow-rate yielded changes of $7 \%$ in the analytical signal in the range under study.

\section{Conclusions}

By taking into account that, (i) there is not and accurate method for total anthocyans, (ii) this value may only be estimated, and that (iii) the polyphenol index (I280) is a relative index of the polyphenol content in wine, the method proposed here enables the simultaneous determination of these two outstanding parameters in red wine with characteristics similar to or better than those of the existing methods. Thus, the proposed method is simple, inexpensive, presents a good correlation with the reference methods used commonly for these analytes and can be easily implemented in a cellar for monitoring red wine fermentation processes. Other advantages of the method reported here are both a sampling throughput higher than that of the methods used routinely in cellars and that it can be easily automated.

This method constitutes a unique simultaneous application of flow injection for determinations in red wine and offers the evident advantage of determining two parameters using the same manifold, thus reducing time and costs.

This is the first time that a continuous simultaneous method for determining total polyphenol index and total anthocyans index is proposed and assessed for its routine use in cellars.

\section{Acknowledgement}

The Spanish Comisión Interministerial de Ciencia y Tecnología (CICyT) is thanked for financial support (Project BQU 2000/0241).

\section{References}

[1] Recueil des méthodes Internationales d'Analyse des Vins et des Mouts, Office International de la vigne et du vin, O.I.V., Paris, France, 1990, p.269.

[2] P. Ribereau-Gayon, E. Stonestreet, Bull. Soc. Chim. 9 (1965) 2649.

[3] J. Oszmianski, C.Y. Lee, Am. J. Enol. Vitic. 41 (1990) 204

[4] B. Berente, D. De la Calle García, M. Reichenbaecher, K. Danzer, J. Chromatogr. A. 871 (2000) 95. 
[5] T.V. Johnston, J.R. Morris, J. Food Sci. 61 (1996) 109.

[6] J. Buitrago, R. Cela, J.A. PérezBustamante, Afinidad 43 (1986) 530.

[7] M. Celeste, C. Tomas, A. Cladera, J.M. Estela, V. Cerdá, Anal. Chim. Acta 269 (1992) 21.

[8] M. Peris-Tortajada, M. PérezCerrada, A. Maquieira, Quim. Anal. 8 (1989) 211.

[9] E. Mataix, M.D. Luque de Castro, Analyst 126 (2001) 251.

[10] E. Mataix, M.D. Luque de Castro, J. Chromatogr. A. 910 (2001) 255. 